\title{
Mannose-binding lectin 2 gene polymorphisms and their association with tuberculosis in a Chinese population
}

Jun-Xian Zhang ${ }^{1,2 \dagger}$, Wen-Ping Gong ${ }^{1 \dagger}$, Dong-Lin Zhu' ${ }^{1}$, Hui-Ru An¹, You-Rong Yang ${ }^{1}$, Yan Liang ${ }^{1}$, Jie Wang ${ }^{1}$, Jing Tang ${ }^{3}$, Wei-guo Zhao ${ }^{4}$ and Xue-Qiong $\mathrm{Wu}^{1 *}$

\begin{abstract}
Background: Immune- and inflammation-related genes (IIRGS) play an important role in the pathogenesis of tuberculosis (TB). However, the relationship between IIRG polymorphisms and TB risk remains unknown. In this study, the gene polymorphisms and their association with tuberculosis were determined in a Chinese population.

Methods: We performed a case-control study involving 1016 patients with TB and 507 healthy controls of Han Chinese origin. Sixty-four single-nucleotide polymorphisms (SNPs) belonging to 18 IIRGs were genotyped by the PCR-MassArray assay, and the obtained data was analyzed with $x^{2}$-test, Bonferroni correction, and unconditional logistic regression analysis.
\end{abstract}

Results: We observed significant differences in the allele frequency of LTA rs $2229094{ }^{*} \mathrm{C}(P=0.015), M B L 2 \mathrm{rs} 2099902 * \mathrm{C}$ $(P=0.001), M B L 2 \mathrm{rs} 930507^{*} \mathrm{G}(P=0.004), M B L 2 \mathrm{rs} 10824793^{*} \mathrm{G}(P=0.004)$, and $I L 12 R B 1 \mathrm{rs} 2305740^{*} \mathrm{G}(P=0.040)$ between the TB and healthy groups. Increased TB risk was identified in the rs $930507 \mathrm{G} / \mathrm{G}$ genotype $\left(P_{\text {adjusted }}=0.027\right)$ under a codominant genetic model as well as in the rs2099902 (C/T +C/C) vs T/T genotype ( $\left.P_{\text {adjusted }}=0.020\right)$, rs930507 (C/G + $\mathrm{G} / \mathrm{G})$ vs $\mathrm{C} / \mathrm{C}$ genotype $\left(P_{\text {adjusted }}=0.027\right)$, and $\mathrm{rs} 10824793(\mathrm{G} / \mathrm{A}+\mathrm{G} / \mathrm{G})$ vs $\mathrm{A} / \mathrm{A}$ genotype $\left(P_{\text {adjusted }}=0.017\right)$ under a dominant genetic model after Bonferroni correction in the analysis of the overall TB group rather than the TB subgroups. Furthermore, the rs10824793_rs7916582*GT and rs10824793_rs7916582*GC haplotypes were significantly associated with increased TB risk ( $P=0.001$, odds ratio $[O R]=1.421,95 \%$ confidence interval [C]: 1.152-1.753; and $P=$ $0.018, O R=1.364,95 \%$ Cl: 1.055-1.765, respectively). Moreover, the rs 10824793_rs7916582*AT/AT or rs 10824793 rs7916582* GT/GT diplotype showed a protective $(P=0.003, O R=0.530,95 \% \mathrm{Cl}: 0.349-0.805)$ or harmful $(P=0.009$, $O R=1.396,95 \%$ Cl: 1.087-1.793) effect against the development of TB.

Conclusions: This study indicated that MBL2 polymorphisms, haplotypes, and diplotypes were associated with TB susceptibility in the Han Chinese population. Additionally, larger sample size studies are needed to further confirm these findings in the future.

Keywords: Tuberculosis, Mannose-binding lectin, Single-nucleotide polymorphism, Genotype, Haplotype

\footnotetext{
*Correspondence: xueqiongwu@139.com

†Jun-Xian Zhang and Wen-Ping Gong contributed equally to this work. 'Army Tuberculosis Prevention and Control Key Laboratory/Beijing Key Laboratory of New Techniques of Tuberculosis Diagnosis and Treatment, Institute for Tuberculosis Research, the 8th Medical Center of Chinese PLA General Hospital, 17\# Heishanhu Road, Haidian District, Beijing 100091, China Full list of author information is available at the end of the article
}

(c) The Author(s). 2020 Open Access This article is licensed under a Creative Commons Attribution 4.0 International License, which permits use, sharing, adaptation, distribution and reproduction in any medium or format, as long as you give appropriate credit to the original author(s) and the source, provide a link to the Creative Commons licence, and indicate if changes were made. The images or other third party material in this article are included in the article's Creative Commons licence, unless indicated otherwise in a credit line to the material. If material is not included in the article's Creative Commons licence and your intended use is not permitted by statutory regulation or exceeds the permitted use, you will need to obtain permission directly from the copyright holder. To view a copy of this licence, visit http://creativecommons.org/licenses/by/4.0/ The Creative Commons Public Domain Dedication waiver (http://creativecommons.org/publicdomain/zero/1.0/) applies to the data made available in this article, unless otherwise stated in a credit line to the data. 


\section{Background}

Tuberculosis (TB) is a global infectious disease in humans. It is a severe and even lethal disease and was responsible for 1.2 million deaths worldwide in 2018 [1]. The main reason worldwide TB eradication is so difficult is that smear-positive TB patients are the most important source of infection. They often transmit the TB bacterium via droplets produced by coughing, sneezing, etc. It was found that a TB patient typically infects 10-15 people from the onset of the disease until diagnosis and treatment and that these infected people can, in turn, become new sources of infection. A healthy person's chances of being infected with Mycobacterium tuberculosis depend on the number of droplets inhaled and duration as well as the individual's immune status.

It is well known that approximately one-third of the world's population is infected with $M$. tuberculosis [1], whereas only $10 \%$ of these infected individuals progress to TB disease [2]. This indicates that the risk of developing $\mathrm{TB}$ in humans is strongly associated with hostpathogen interactions, the environment, and genetic background [3]. Recently, a growing number of studies has supported the hypothesis that TB risk is associated with polymorphisms of immune- and inflammationrelated genes (IIRGs), including the interleukin-10 (IL10), IL1A,IL1B, IL6, IL12B, IL27, interleukin 12 receptor beta 1 (IL12RB1), interleukin 18 receptor 1 (IL18R1), signal transducer and activator of transcription 1 (STAT1), natural resistance-associated macrophage protein 1 (SLC11A1 or NRAMP1), SP110, lymphotoxin A (LTA), tumor necrosis factor (TNF), interferon gamma receptor 1 (IFNGR1), IFNGR2, mannose-binding lectin 2 (MBL2), vitamin $\mathrm{D}$ receptor $(V D R)$, monocyte chemoattractant protein-1 $(M C P-1$ or $C C L 2)$, and toll-like receptor 8 (TLR8) genes [4-13]. IIRGs play essential roles in innate and adaptive immunity, which help control $M$. tuberculosis infection in humans [14]. Therefore, polymorphisms in these genes can alter immunity and lead to genetic susceptibility to TB. Moreover, common genetic variants of IIRGs could be used to predict and evaluate TB risk in the early stages of infection.

However, previous studies have mostly focused on the association between polymorphisms in one or several related genes and susceptibility to $\mathrm{TB}$, rather than multiple IIRGs. It is well known that the interaction between $M$. tuberculosis and its host leads to a very complex immune response. As such, studies that focus on a single or a small number of sample genes may overlook potential associations between multiple genes: for example, they may ignore linkage disequilibrium between numerous single-nucleotide polymorphisms (SNPs). Therefore, it is imperative to study the association between various SNPs and susceptibility to TB in as many IIRGs as possible.
In this study, 64 SNPs in 18 IIRGs were selected, and the association between these SNPs and TB risk was evaluated using the polymerase chain reaction (PCR)MassArray method in a large case-control population of Han Chinese origin.

\section{Methods}

\section{Patients, controls, and ethics statement}

This case-control study was performed in the 8th Medical Center of Chinese PLA General Hospital (Beijing, China) from June 2009 to March 2019 and was approved by the Research Ethics Committee of the 8th Medical Center of the Chinese PLA General Hospital. All DNA samples were extracted from residual blood after a liver function test. Informed consent was obtained from all participants. In total, 1016 patients (597 males and 419 females, mean age $39.5 \pm 19.3$ years) with a TB diagnosis according to smear, $M$. tuberculosis culture, radiological examination, and histological examination were randomly included from the patients in the 8th Medical Center of the Chinese PLA General Hospital (Beijing, China). In the same period, 507 healthy volunteers (289 males and 218 females, mean age $51.8 \pm 10.6$ years) with retrospectively confirmed non-tuberculous diseases were included from the physical examination center of 8th Medical Center of the Chinese PLA General Hospital. All TB and control patients were HIV negative.

\section{DNA extraction}

Blood samples $(2 \mathrm{ml})$ from each participant were collected (the residual portion of the blood samples obtained for a liver function test) and stored in citrateanticoagulated glass tubes at $-40{ }^{\circ} \mathrm{C}$ until use. The Whole Blood DNA Extraction Kit (Tiangen Biotech, Co., Ltd., Beijing, China) was used to extract total genomic DNA from $1 \mathrm{ml}$ of the stored blood samples, following the manufacturer's instructions. Then, the extracted genomic DNA was resuspended in $0.1 \times$ Tris-EDTA buffer $(10 \mathrm{mmol} / \mathrm{L}$ Tris, $1 \mathrm{mmol} / \mathrm{L}$ EDTA, $\mathrm{pH} 8.0)$ and stored at $-20^{\circ} \mathrm{C}$.

\section{Screening of target SNPs}

Data from the International HapMap Project (http:// hapmap.ncbi.nlm.nih.gov) were used to screen potential SNPs using an estimated $r^{2}$ threshold of $>0.8$ for the untyped SNPs as reported in a previous study [15]. The genotype data for the Han Chinese population were obtained from the Haploview 4.2 program (http://www. broad.mit.edu/haploview) and used to select SNPs that have a minor allele frequency (MAF) of $>0.05$.

\section{Genotyping}

In total, 64 SNPs of IL-10, IL18R1, IL1A, IL1B, STAT1, SLC11A1, SP110, IL12B, LTA, TNF, IFNGR1, MBL2, 
VDR, IL27, CCL2, IL12RB1, IFNGR2, and TLR8 were genotyped in samples from both TB patients and controls using the iPLEX assay on a MassArray system (Sequenom Inc., San Diego, United States) according to a previously published protocol [16]. The main particularities are listed below: (1) PCR reactions: Genomic DNA (10 ng), Taq DNA polymerase (0.5 U, HotStarTaq, Qiagen, Shanghai, China), dNTPs $(500 \mu \mathrm{mol})$, and PCR primers $(100 \mathrm{nmol})$ in a $5-\mu \mathrm{l}$ reaction volume were added into a 384-well plate. Then, PCR thermal cycling was performed at $94{ }^{\circ} \mathrm{C}$, followed by 45 cycles of $20 \mathrm{~s}$ at $94^{\circ} \mathrm{C}$, $30 \mathrm{~s}$ at $56^{\circ} \mathrm{C}$, and $60 \mathrm{~s}$ at $72{ }^{\circ} \mathrm{C}$ using an ABI-9700 instrument (Thermo Fisher Scientific Inc., Waltham, United States). Finally, the PCR products were examined by 2.0\% agarose gel electrophoresis. (2) Purification: After the PCR reaction, $2 \mu \mathrm{l}$ of shrimp alkaline phosphatase $(0.3 \mathrm{U})$ was mixed with the PCR products, incubated at $37^{\circ} \mathrm{C}$ for $20 \mathrm{~min}$, and then inactivated at $85^{\circ} \mathrm{C}$ for $5 \mathrm{~min}$. (3) Extension: The concentrations of the extension primers were adjusted to equilibrate the signal-to-noise ratios. Then, termination mix $(100 \mu \mathrm{mol})$, DNA polymerase ( $0.05 \mathrm{U}$, Sequenom, Inc., San Diego, United States), and extension primers (625 to $1250 \mathrm{nmol} / \mathrm{L}$ ) in a final volume of $9 \mu \mathrm{l}$ were pooled together and detected using an iPLEX Gold Kit (Sequenom, Inc., San Diego, United States) at $94{ }^{\circ} \mathrm{C}$ for $30 \mathrm{~s}$, followed by $5 \mathrm{~s}$ at $94{ }^{\circ} \mathrm{C}$ and 5 cycles of $5 \mathrm{~s}$ at $52{ }^{\circ} \mathrm{C}$ and $5 \mathrm{~s}$ at $80^{\circ} \mathrm{C}$. An additional 40 annealing and extension cycles were then performed, with $5 \mathrm{~s}$ at $94{ }^{\circ} \mathrm{C}$ and 5 cycles of $5 \mathrm{~s}$ at $52^{\circ} \mathrm{C}$ and $5 \mathrm{~s}$ at $80^{\circ} \mathrm{C}$. The final extension was carried out at $72{ }^{\circ} \mathrm{C}$ for $3 \mathrm{~min}$; then, the sample was cooled to $4{ }^{\circ} \mathrm{C}$. (4) MALDI-TOF-MS: The samples were then manually desalted using $6 \mathrm{mg}$ of clean resin and a dimple plate and subsequently transferred to a 384-well SpectroCHIP (Sequenom, Inc., San Diego, United States) using a nano-dispenser. The mass spectra were acquired using the Compact Mass Spectrometer and analyzed via the MassArray Typer 4.0 Software (Sequenom, Inc., San Diego, United States). The PCR assay was performed with two no-template controls and four duplicated samples in each 384-well format as quality controls. Each genotyping result was generated and analyzed by laboratory staff who were unaware of the patient's status.

\section{Statistical analyses}

All statistical analyses were performed using the Stata statistical package (version 10.0; StataCorp LP, College Station, TX, USA), and all $P$ values were two-tailed. The statistical differences in allele and genotype frequencies between the TB and control groups were evaluated using the $\chi^{2}$-test. In the $\chi^{2}$-test, $P$ values with a Bonferroni correction of $<0.05$ were considered significant. The Hardy-Weinberg Equilibrium (HWE) was tested via the $X^{2}$-test for goodness of fit using a web program (http:// ihg.gsf.de/cgi-bin/hw/hwa1.pl). Moreover, Akaike's information criterion was used to select the genetic model with maximum parsimony for each SNP. Odds ratios $(O R s)$ as well as $95 \%$ confidence intervals $(\mathrm{CIs})$ were calculated via unconditional logistic regression analysis with adjustment for age and gender.

The pairwise linkage disequilibrium (LD) among the SNPs was determined using Lewontin's standardized coefficient D' and LD coefficient $r^{2}$ as described in a previous study [17], whereas haplotype blocks were defined in Haploview 4.2 (https://www.broadinstitute.org/haploview/haploview) with default settings following the criteria published in a previous study [18]. In addition, the haplotype frequencies were estimated using the PHASE 2.1 Bayesian algorithm [19] and HAPLO.STATS [20]. The haplotypes were then pooled into a combined group if their frequency was less than 0.03 . Empirical $P$ values, based on 100000 simulations, were computed for the global score test and each of the haplotype-specific score tests. The diplotype (haplotype dosage, an estimate of the number of copies of the haplotype) was the most probable haplotype pair for each individual. Unconditional logistic regression analysis was used to evaluate the ORs and 95\% CIs for participants carrying 1 to 2 copies versus 0 copies of each common haplotype for the dichotomized diplotypes.

\section{Results}

The distribution of 64 SNP alleles in TB patients and healthy controls

One thousand and sixteen patients with a TB diagnosis and 507 healthy controls were recruited. Among the TB patients, $680(66.9 \%)$ had total pulmonary TB (TPTB), including 388 with simple PTB and 74 with simple TB pleurisy (TBP), 166 (16.3\%) had extrapulmonary TB (EPTB), and 170 (16.7\%) had concomitant PTB and ЕРТВ (РTB + EPTB).

Sixty-four SNPs from 18 IIRGs were selected and genotyped, and all allele distributions in the control group were consistent with those from the HWE $(P>0.01$, Table 1). The results showed that the allele distributions of $L T A$ rs $2229094 * \mathrm{C}(P=0.015), M B L 2$ rs2099902*C $(P=0.001), \quad M B L 2 \quad \mathrm{rs} 930507^{*} \mathrm{G} \quad(P=0.004), \quad M B L 2$ rs10824793*G $(P=0.004)$, and IL12RB1 rs2305740*G $(P=0.040)$ were significantly different between the TB patients and healthy controls (Table 1 ), whereas the allele distributions of the other SNPs were not.

\section{The genotypic frequencies of SNPs and their associations with TB risk}

When investigating the TB group, the unconditional logistic regression analysis showed that 14 SNPs of IL18R1, IL1A, STAT1, LTA, IFNGR1, MBL2, VDR, and IL12RB1 were associated with TB risk under a 


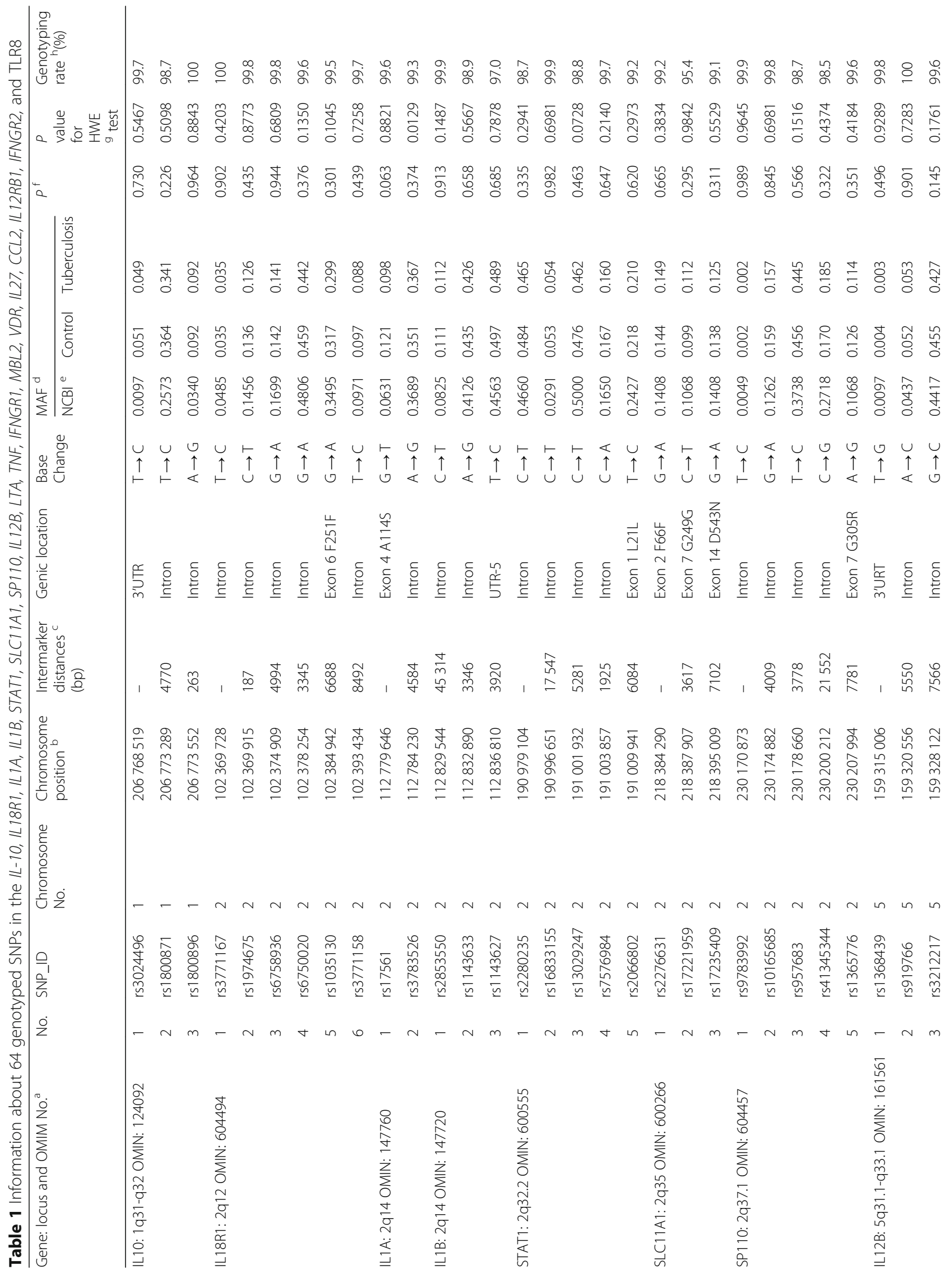




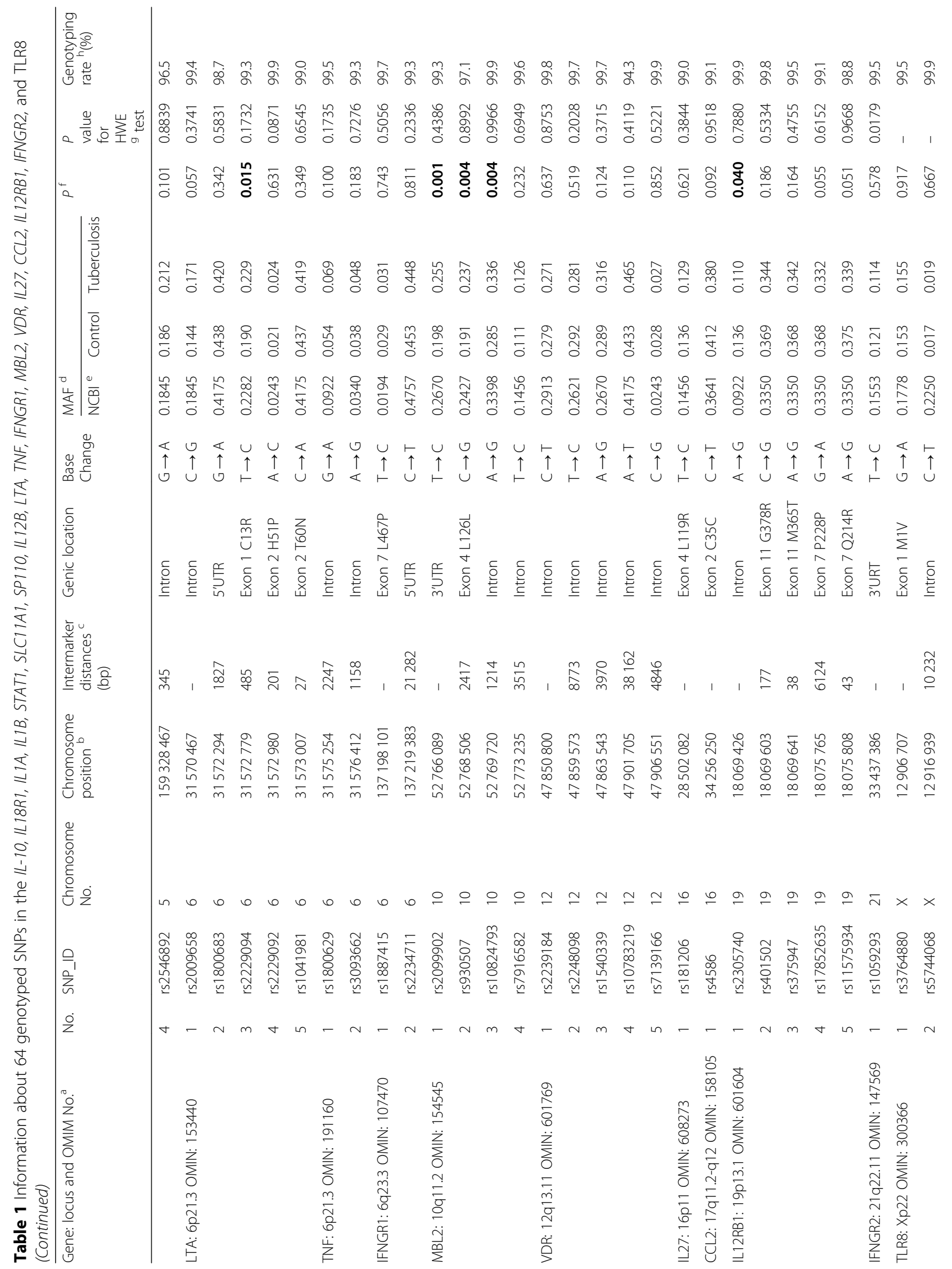




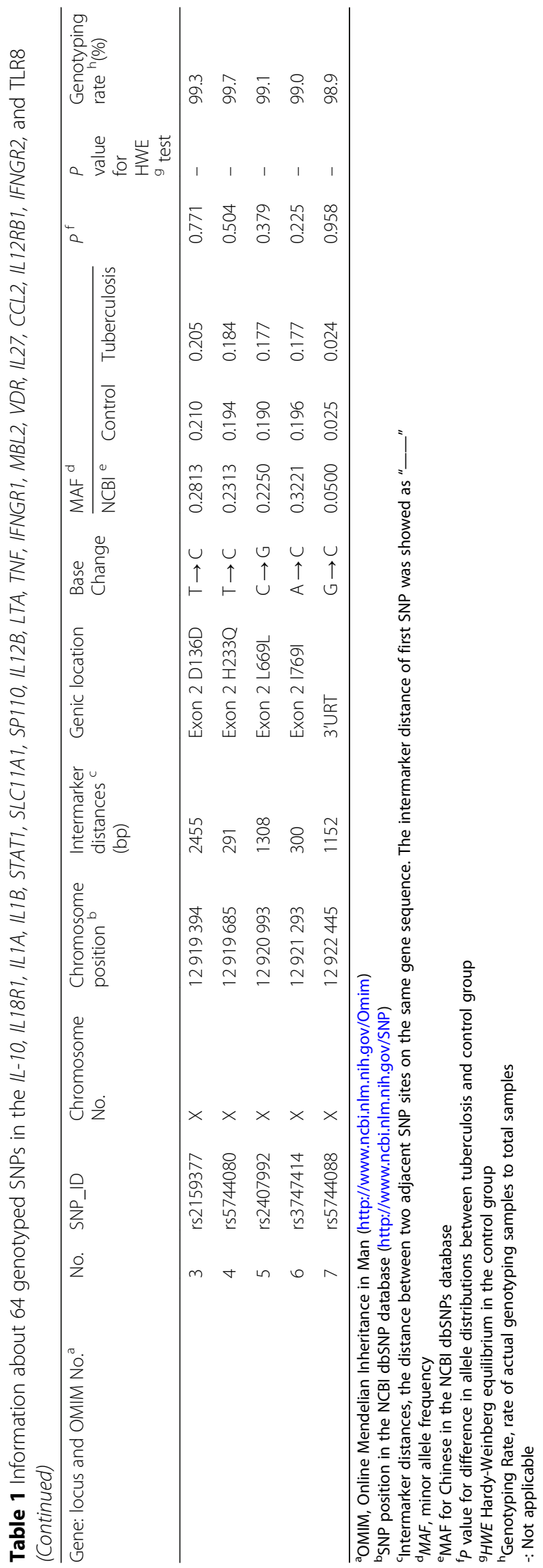


Table 2 Genotype frequencies of SNPs in the MBL2 gene among cases and controls and their associations with tuberculosis risk under a codominant genetic model

\begin{tabular}{|c|c|c|c|c|c|c|c|c|c|}
\hline \multirow[t]{2}{*}{ SNP ID } & \multirow[t]{2}{*}{ Genotype } & \multicolumn{2}{|c|}{ Case (TB) } & \multicolumn{2}{|c|}{ Control } & \multirow{2}{*}{$\begin{array}{l}P(2 \\
d f)^{a}\end{array}$} & \multicolumn{3}{|l|}{ Logistic Regression } \\
\hline & & No. & $\overline{\text { Frequency }}$ & No. & $\overline{\text { Frequency }}$ & & OR (95\% Cl) & $p^{b}$ & $P_{\text {adjusted }}$ \\
\hline \multirow[t]{3}{*}{ rs2099902 } & $\mathrm{T} / \mathrm{T}$ & 552 & $55.8 \%$ & 323 & $63.8 \%$ & 0.0025 & 1.000 (referent) & & \\
\hline & $C / T$ & 372 & $37.6 \%$ & 166 & $32.8 \%$ & & $2.364(1.317-4.244)$ & 0.004 & 0.256 \\
\hline & $\mathrm{C} / \mathrm{C}$ & 66 & $6.7 \%$ & 17 & $3.4 \%$ & & $1.459(1.143-1.863)$ & 0.002 & 0.128 \\
\hline \multirow[t]{3}{*}{ rs930507 } & $\mathrm{C} / \mathrm{C}$ & 549 & $57.3 \%$ & 330 & $65.4 \%$ & 0.0149 & 1.000 (referent) & & \\
\hline & $C / G$ & 363 & $37.9 \%$ & 157 & $31.1 \%$ & & $1.556(1.215-1.992)$ & $4.218 \mathrm{E}-4$ & 0.027 \\
\hline & $\mathrm{G} / \mathrm{G}$ & 46 & $4.8 \%$ & 18 & $3.6 \%$ & & $1.672(0.921-3.038)$ & 0.091 & 1.000 \\
\hline \multirow[t]{3}{*}{ rs10824793 } & $\mathrm{A} / \mathrm{A}$ & 434 & $43.4 \%$ & 259 & $51.2 \%$ & 0.0171 & 1.000 (referent) & & \\
\hline & $\mathrm{G} / \mathrm{A}$ & 459 & $46.0 \%$ & 206 & $40.7 \%$ & & $1.466(1.153-1.863)$ & 0.002 & 0.128 \\
\hline & $\mathrm{G} / \mathrm{G}$ & 106 & $10.6 \%$ & 41 & $8.1 \%$ & & $1.890(1.245-2.870)$ & 0.003 & 0.192 \\
\hline \multirow[t]{3}{*}{ rs7916582 } & $\mathrm{T} / \mathrm{T}$ & 762 & $76.3 \%$ & 398 & $79.3 \%$ & 0.3794 & 1.000 (referent) & & \\
\hline & $\mathrm{T} / \mathrm{C}$ & 223 & $22.3 \%$ & 97 & $19.3 \%$ & & 1.338 (1.006-1.779) & 0.045 & 1.000 \\
\hline & $\mathrm{C} / \mathrm{C}$ & 14 & $1.4 \%$ & 7 & $1.4 \%$ & & $1.134(0.424-3.034)$ & 0.803 & 1.000 \\
\hline
\end{tabular}

${ }^{\mathrm{a}}$ Global $P$ values (2 degrees of freedom [df]): genotype frequencies in tuberculosis and control group were compared using a $X^{2}$ test with two $\mathrm{df}$

${ }^{\mathrm{b}} P$ values from unconditional logistic regression analyses, adjusted for age and gender

${ }^{c} P_{\text {adjusted }} P$ value with Bonferroni correction, $P_{\text {adjusted }}$ value less than 0.05 was considered to be significant

codominant model (Table S1) and under a dominant and recessive genetic model (Table S2). However, after adjusting for the Bonferroni correction, only SNPs in the $M B L 2$ gene were found to still be associated with TB risk. Therefore, we next focused on the $M B L 2$ gene. Our results showed that: 1) Under a codominant genetic model (Table 2), the rs2099902 $\mathrm{C} / \mathrm{T}$ and $\mathrm{C} / \mathrm{C}$ genotypes, rs930507 C/G genotype, rs10824793 G/A and G/G genotypes, and rs7916582 T/C genotype were associated with increased risk of TB. After the Bonferroni correction, increased TB risk was still observed in patients with a rs930507 G/G genotype ( $\left.P_{\text {adjusted }}=0.027\right)$. 2) Under a dominant and recessive genetic model (Table 3 ), the rs2099902 $(\mathrm{C} / \mathrm{T}+\mathrm{C} / \mathrm{C})$ vs $\mathrm{T} / \mathrm{T}$ and $\mathrm{C} / \mathrm{C}$ vs $(\mathrm{T} / \mathrm{T}+\mathrm{C} / \mathrm{T})$ genotypes, rs930507 (C/G+G/G) vs $\mathrm{C} / \mathrm{C}$ genotype, rs10824793 (G/A + G/G) vs A/A as well as $\mathrm{G} / \mathrm{G}$ vs (A/ $\mathrm{A}+\mathrm{G} / \mathrm{A})$ genotypes, and rs7916582 $(\mathrm{T} / \mathrm{C}+\mathrm{C} / \mathrm{C})$ vs $\mathrm{T} / \mathrm{T}$ genotype were associated with increased risk of TB. Interestingly, increased TB risk was still observed for the rs2099902 $\left(P_{\text {adjusted }}=0.020\right)$, rs930507 $\left(P_{\text {adjusted }}=0.027\right)$, and rs10824793 ( $P_{\text {adjusted }}=0.017$ ) SNPs under a dominant genetic model after the Bonferroni correction.

\section{The distribution of the MBL2 SNP genotype frequency}

To further confirm the differences in the distribution of the $M B L 2$ SNP genotype frequency between the TB subgroups (TPTB, PTB, EPTB, and $\mathrm{PTB}+\mathrm{EPTB}$ ) and healthy controls, we performed unconditional logistic regression analysis under codominant, dominant, and recessive genetic models. The results indicated that the rs2099902 C/T and C/C genotypes, rs930507 C/G genotype, rs10824793 G/A and G/G genotypes were associated with increased TB risk in the TB subgroups (Table S3). However, these statistically significant differences

Table 3 Association analysis of SNPS in the MBL2 gene under a dominant and recessive genetic model

\begin{tabular}{|c|c|c|c|c|c|c|}
\hline \multirow[t]{2}{*}{ SNP ID } & \multirow[t]{2}{*}{ Genetic model } & \multirow[t]{2}{*}{ Case } & \multirow[t]{2}{*}{ Control } & \multicolumn{3}{|l|}{ Logistic Regression } \\
\hline & & & & OR $(95 \% C l)$ & $p^{a}$ & $P_{\text {adjusted }}{ }^{b}$ \\
\hline \multirow[t]{2}{*}{ rs2099902 } & $(\mathrm{C} / \mathrm{T}+\mathrm{C} / \mathrm{C})$ vs $\mathrm{T} / \mathrm{T}$ & $438 / 552$ & $183 / 323$ & $1.544(1.220-1.954)$ & $3.023 \mathrm{E}-3$ & 0.020 \\
\hline & $\mathrm{C} / \mathrm{C}$ vs $(\mathrm{T} / \mathrm{T}+\mathrm{C} / \mathrm{T})$ & $66 / 924$ & $17 / 489$ & 2.055 (1.154-3.659) & 0.014 & 0.896 \\
\hline \multirow[t]{2}{*}{ rs930507 } & $(\mathrm{C} / \mathrm{G}+\mathrm{G} / \mathrm{G})$ vs $\mathrm{C} / \mathrm{C}$ & $409 / 549$ & $175 / 330$ & $1.568(1.235-1.990)$ & $2.211 \mathrm{E}-4$ & 0.027 \\
\hline & $\mathrm{G} / \mathrm{G}$ vs $(\mathrm{C} / \mathrm{C}+\mathrm{C} / \mathrm{G})$ & $46 / 912$ & $18 / 487$ & $1.425(0.790-2.568)$ & 0.239 & 1.000 \\
\hline \multirow[t]{2}{*}{ rs10824793 } & $(G / A+G / G)$ vs $A / A$ & $565 / 434$ & $247 / 259$ & 1.533 (1.219-1.927) & $2.544 \mathrm{E}-4$ & 0.017 \\
\hline & $G / G$ vs $(A / A+G / A)$ & 106/893 & $41 / 465$ & $1.571(1.052-2.345)$ & 0.027 & 1.000 \\
\hline \multirow[t]{2}{*}{ rs7916582 } & $(T / C+C / C)$ vs $T / T$ & $237 / 762$ & $104 / 398$ & $1.324(1.003-1.748)$ & 0.047 & 1.000 \\
\hline & $C / C$ vs $(T / T+T / C)$ & $14 / 985$ & $7 / 495$ & $1.065(0.399-2.841)$ & 0.900 & 1.000 \\
\hline
\end{tabular}

${ }^{a} P$ values from unconditional logistic regression analyses, adjusted for age and gender

${ }^{\mathrm{b}} P_{\text {adjusted }} P$ value with Bonferroni correction, the $P_{\text {adjusted }}$ value less than 0.05 was considered to be significant 
disappeared after applying the Bonferroni correction under a codominant genetic model ( $P_{\text {adiusted }}>0.05$, Table S3). A similar result was observed under the dominant and recessive genetic model $\left(P_{\text {adjusted }}>0.05\right.$, Table S4).

\section{The distribution of the MBL2 haplotypes and diplotypes}

To investigate the associations regarding LD patterns between these four SNPs, we used Haploview to plot their haplotype blocks. We identified one haplotype block composed of rs10824793 and rs7916582 $\left(r^{2}=0.98\right)$. However, the rs2099902 and rs930507 SNPs in the MBL2 gene were outside this haplotype block (Fig. 1). In the haplotype analysis, three common haplotypes (rs10824793_rs7916582*AT, GT,

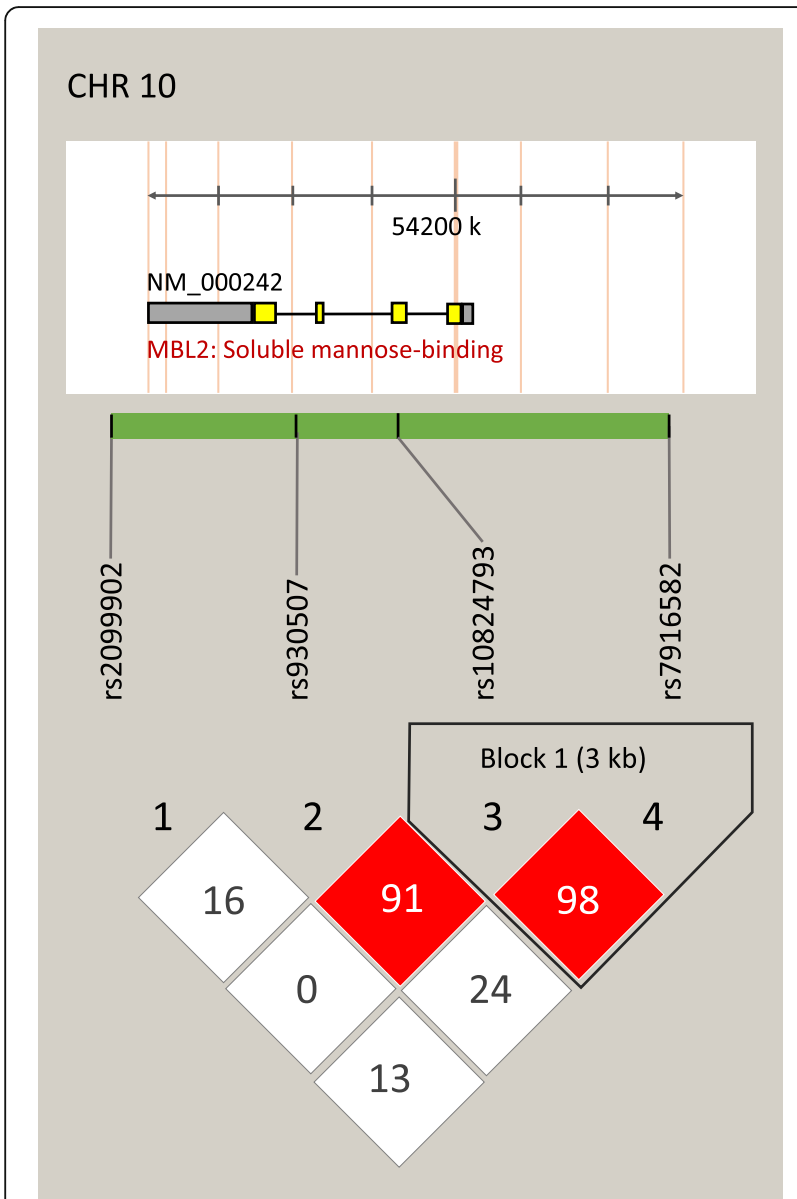

Fig. 1 Location and linkage disequilibrium structure for the four SNPS in the MBL2 gene. The SNP distribution and haplotype block structure across four SNPs in the MBL2 gene are shown, respectively. The figure was composed of chromosome-scale (the top line with even division), the transcription string (the thick bar represents exon (yellow), or UTR (grey), and the thin line represent intron), SNP scale (the hollow bar with scales representing SNPs location), and graphic of LD (black-and-green) or block definition (flammulated).

Correlation coefficients $\left(r^{2}, \times 100\right)$ are shown in the individual boxes; the color from white to red denotes $r^{2}$ from 0 to 1 . LD, linkage disequilibrium; UTR, Untranslated Regions and GC) were observed among the participants; the total percentage of these common haplotypes was as high as $99.85 \%$ in the TB group or $99.9 \%$ in the control group. Conversely, the total percentage of other haplotypes was only $0.15 \%$ or $0.10 \%$ in the TB or control group, respectively (Table 4). The global score test indicated that the frequency of the haplotypes from the block between the TB and control groups was significantly different (global $P=0.00222, P_{\text {sim }}=$ 0.00207). Interestingly, statistical differences were observed in the frequency of the rs10824793_rs7916582*AT $(P=$ 0.00014) or rs10824793_rs7916582*GT $(P=0.003)$ haplotype between the TB and control groups. Moreover, this difference remained significant after the Bonferroni correction (rs10824793_rs7916582*AT, $P_{\text {adjusted }}=0.00042$; rs10824793 rs7916582*GT, $P_{\text {adjusted }}=0.009$ ). Furthermore, the rs1082 4793_rs7916582*GT or rs10824793_rs7916582*GC haplotype was significantly associated with increased TB risk $(P=$ 0.001, OR: 1.421, 95\% CI: 1.152-1.753; or $P=0.018$, OR: 1.364, 95\% CI: 1.055-1.765) in the logistic regression analysis when compared to the rs10824793_rs7916582*AT haplotype (Table 4).

Moreover, the association between the diplotypes of the $M B L 2$ gene polymorphisms and TB risk was also analyzed. As shown in Table 5, the diplotype composed of the rs10824793_rs7916582*AT haplotypes had a considerably decreased TB risk in a 2-copy logistic regression analysis compared with 0 -copy $(P=0.003, O R=0.530,95 \% C I$ : $0.349-0.805)$. Moreover, this significant protective effect was still observed after Bonferroni correction $\left(P_{\text {adjusted }}=\right.$ 0.009). In contrast, increased TB risk was found in the diplotype composed of the rs10824793_rs7916582*GT $(P=0.009, \quad O R=1.396, \quad 95 \% \quad C I: \quad 1.087-1.793)$ or rs10824793_rs7916582 $\% \mathrm{GC}(P=0.05, O R=1.330,95 \% C I$ : $1.000-1.768)$ haplotypes in 1-copy logistic regression analysis compared with 0-copy. However, this significant difference was only observed in the diplotype composed of the rs10824793_rs7916582*GT haplotype after Bonferroni correction $\left(P_{\text {adjusted }}=0.027\right)$.

\section{Discussion}

In this study, we genotyped 64 SNPs from 18 IIRGs in a Han Chinese population. We first showed that the rs930507 G/G, rs2099902 $[(\mathrm{C} / \mathrm{T}+\mathrm{C} / \mathrm{C}) \quad$ vs $\mathrm{T} / \mathrm{T}]$, rs930507 $[(\mathrm{C} / \mathrm{G}+\mathrm{G} / \mathrm{G})$ vs $\mathrm{C} / \mathrm{C}]$, and $\mathrm{rs} 10824793[(\mathrm{G} /$ $A+G / G)$ vs $A / A$ ] genotypes were risk factors for $T B$ under a codominant or dominant genetic model in $\mathrm{TB}$ patients and healthy controls (Fig. 2). Interestingly, these significant associations were not observed under any genetic model between subgroups of the TB patients and controls. This may be attributed to the low number of patients included in each tuberculosis subgroup. Therefore, to further improve the accuracy of the study, the sample size of each tuberculosis subgroup should be increased in the future. 
Table 4 Haplotypes analysis of MBL2 gene polymorphisms with tuberculosis risk

\begin{tabular}{|c|c|c|c|c|c|c|c|c|c|c|}
\hline \multirow[t]{2}{*}{ Haplotype } & \multicolumn{2}{|c|}{ Tuberculosis } & \multicolumn{2}{|c|}{ Control } & \multirow[t]{2}{*}{$P^{a}$} & \multirow[t]{2}{*}{$P_{\text {adjusted }} \mathrm{b}$} & \multirow{2}{*}{$\begin{array}{l}\text { Hap. } \\
\text { Score }\end{array}$} & \multicolumn{2}{|l|}{ Logistic Regression } & \multirow[t]{2}{*}{ Global score test } \\
\hline & No. & Frequency & No. & Frequency & & & & OR $(95 \%$ Cl) & $p^{d}$ & \\
\hline \multicolumn{10}{|c|}{ Block 1: rs10824793-rs7916582 } & \multirow{5}{*}{$\begin{array}{l}\text { Global-stat }=14.57143 \\
\mathrm{df}^{\mathrm{e}}=3, P=0.00222, \mathrm{P}_{\text {sim }}=0.00207\end{array}$} \\
\hline AT & 1328 & $66.3 \%$ & 723 & $71.4 \%$ & 0.00014 & 0.00042 & -3.8039 & 1.000 (referent) & & \\
\hline GT & 423 & $21.1 \%$ & 177 & $17.5 \%$ & 0.003 & 0.009 & 2.9843 & $1.421(1.152-1.753)$ & 0.001 & \\
\hline GC & 248 & $12.4 \%$ & 111 & $11.0 \%$ & 0.077 & 0.231 & 1.7679 & $1.364(1.055-1.765)$ & 0.018 & \\
\hline Others & 3 & $0.2 \%$ & 1 & $0.1 \%$ & - & - & - & - & - & \\
\hline
\end{tabular}

${ }^{a} P$ value for difference in the haplotype frequency between tuberculosis and control group

${ }^{\mathrm{b}} P_{\text {adjusted }} P$ value with Bonferroni correction, $P_{\text {adjusted }}$ value less than 0.05 was considered to be significant

${ }^{\mathrm{C}} \mathrm{A}$ positive (or negative) score for a particular haplotype would have suggested that the haplotype was associated with increased (or decreased) risk

of Tuberculosis

${ }^{\mathrm{d}} P$ values from unconditional logistic regression analyses, adjusted for age and gender

e $d f$ degrees of freedom

The MBL protein is encoded by the MBL2 gene and is secreted in the liver, where it activates the complement system via the lectin pathway to combat pathogens during host infection [21]. Although the mechanisms by which the $M B L 2$ mutations regulate TB progression remain unclear, there is no doubt that $M B L 2$ plays a vital role in the pathophysiology of TB. To our knowledge, this is the first study to report that the rs930507, rs2099902, and rs10824793 polymorphisms can affect TB development in a population of Han Chinese origin. It is worth mentioning that several meta-analysis studies have reported that five MBL2 SNPs (rs1800450, rs1800451, rs5030737, rs7095891, and rs7096206) are associated with an increased or decreased TB risk [22-26]. However, there is insufficient data regarding the role of rs930507, rs2099902, and rs10824793 in TB susceptibility. Several studies on diseases other than TB have revealed that rs930507 was associated with an increased risk of invasive pneumococcal disease (IPD) in African Americans [27] and otitis media in children younger than 2 years of age [28]. Moreover, it was also shown to be associated with sodium-lithium countertransport (SLC) and systolic blood pressure [29]. Previous studies have found no association between rs2099902 and recurrent vulvovaginal infections risk [30] or severe dengue [31]; however, another study performed by Zanetti et al. suggested that rs2099902 was associated with increased risk of colon cancer in African Americans [32]. These data indicate that the susceptibility and pathogenicity of the same SNP were different in various diseases. As such, the mechanisms that underlie these differences might deserve further investigation.

The above-mentioned evidence indicated an association between the $M B L 2$ gene and TB risk genotypes. Herein, we found an association between them by linkage disequilibrium, haplotype, and diplotype analyses. In this study (Fig. 2), the rs7916582 polymorphism was not found to be significantly associated with TB susceptibility. However, when the rs10824793 and rs7916582 SNPs were combined in haplotypes, the rs $10824793 * \mathrm{G} /$ rs7916582*T and rs10824793*G/rs7916582*C alleles were found to be significantly associated with TB risk, which is similar to the haplotype block rs7095891*G/ rs $1800450 * \mathrm{C} / \mathrm{rs} 1800451^{*} \mathrm{C} / \mathrm{rs} 4935047^{*} \mathrm{~A} / \mathrm{rs} 930509^{*} \mathrm{G} /$ rs2120131* $\mathrm{G} / \mathrm{rs} 2099902 * \mathrm{C}$ yielded by $\mathrm{LD}$ analysis in a previous study [31]. LD is the non-random combination of alleles at different loci and is influenced by several factors, such as selection, genetic drift, recombination rate, mutation rate, and population structure as well as genetic linkage. A haplotype is a group of genes in an organism that are inherited together from a single parent. Haplotypes are critical for investigating the genetics of

Table 5 Diplotypes analysis of MBL2 gene polymorphisms with tuberculosis risk

\begin{tabular}{|c|c|c|c|c|c|c|c|c|c|c|}
\hline \multirow[t]{2}{*}{ Haplotype } & \multicolumn{2}{|l|}{ 0-copy } & \multicolumn{4}{|c|}{ 1-copy Logistic Regression } & \multicolumn{4}{|c|}{ 2-copy Logistic Regression } \\
\hline & $\begin{array}{l}\text { Case/ } \\
\text { Control }\end{array}$ & OR $(95 \% C l)$ & $\begin{array}{l}\text { Case/ } \\
\text { Control }\end{array}$ & $P^{a}$ & $P_{\text {adjusted }} \mathrm{b}$ & OR $(95 \% C l)$ & $\begin{array}{l}\text { case/ } \\
\text { control }\end{array}$ & $P^{a}$ & $P_{\text {adjusted }} \mathrm{b}$ & OR $(95 \% C l)$ \\
\hline $\begin{array}{l}\text { rs10824793_- } \\
\text { rs7916582*AT }\end{array}$ & $106 / 41$ & $\begin{array}{l}1.000 \\
\text { (referent) }\end{array}$ & $462 / 207$ & 0.235 & 0.705 & $\begin{array}{l}0.775 \\
(0.509-1.180)\end{array}$ & $433 / 258$ & 0.003 & 0.009 & $\begin{array}{l}0.530 \\
(0.349-0.805)\end{array}$ \\
\hline $\begin{array}{l}\text { rs10824793_- } \\
\text { rs7916582*GT }\end{array}$ & $622 / 345$ & $\begin{array}{l}1.000 \\
\text { (referent) }\end{array}$ & $335 / 145$ & 0.009 & 0.027 & $\begin{array}{l}1.396 \\
(1.087-1.793)\end{array}$ & $44 / 16$ & 0.101 & 0.303 & $\begin{array}{l}1.684 \\
(0.904-3.136)\end{array}$ \\
\hline $\begin{array}{l}\text { rs10824793_- } \\
\text { rs7916582*GC }\end{array}$ & $767 / 402$ & $\begin{array}{l}1.000 \\
\text { (referent) }\end{array}$ & 220/97 & 0.05 & 0.15 & $\begin{array}{l}1.330 \\
(1.000-1.768)\end{array}$ & $14 / 7$ & 0.797 & 2.391 & $\begin{array}{l}1.138 \\
(0.426-3.041)\end{array}$ \\
\hline
\end{tabular}

${ }^{a} P$ values from unconditional logistic regression analyses, adjusted for age and gender

${ }^{\mathrm{b}} P_{\text {adjusted }} P$ value with Bonferroni correction, $P_{\text {adjusted }}$ value less than 0.05 was considered to be significant 


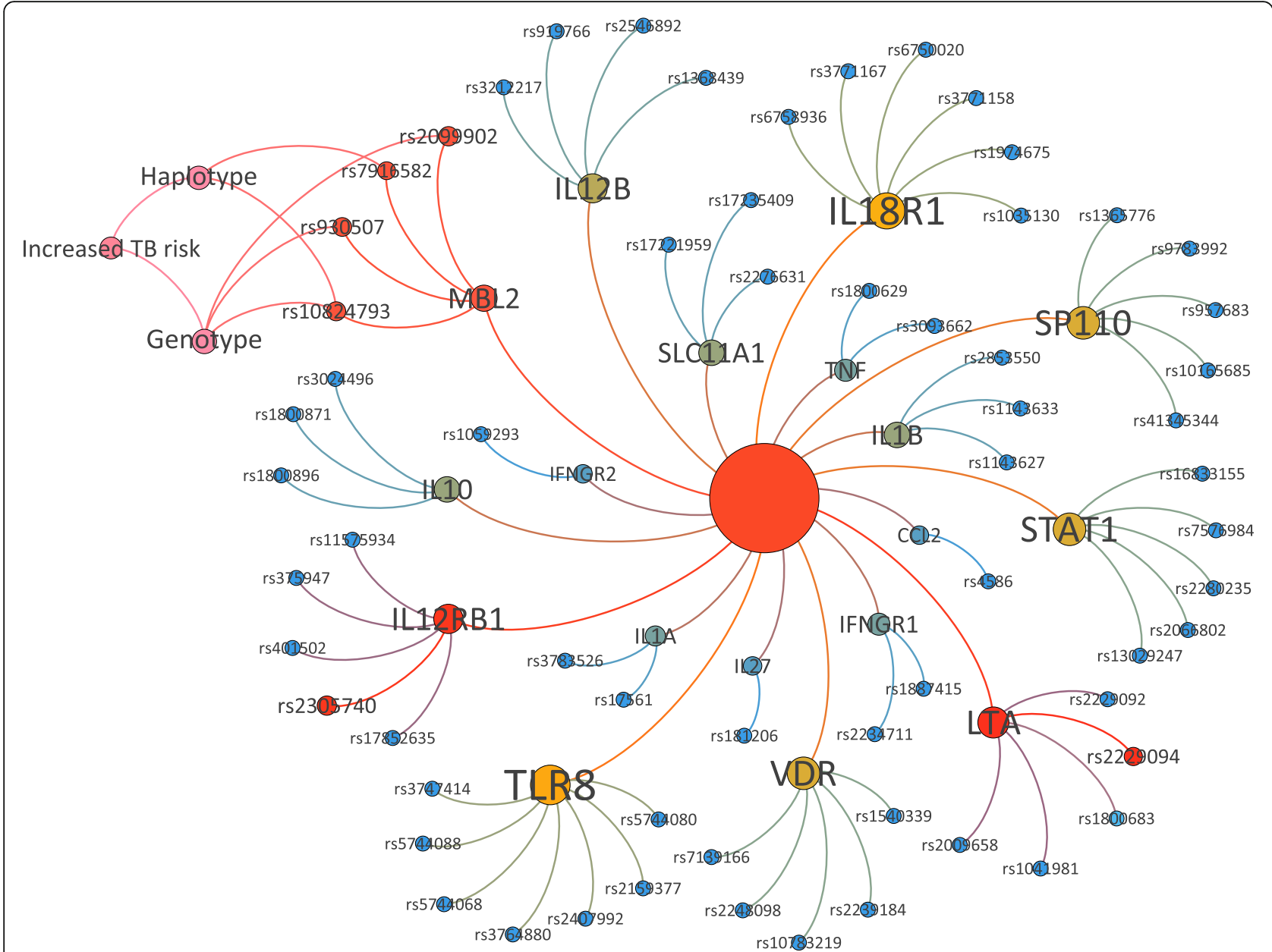

Fig. 2 Neural network diagram of 64 SNPs in the 18 immune- and inflammation-related genes (IIRGs). The neural network diagram was plotted using an open-source graph visualization and manipulation software termed Gehpi. In the present figure, 18 genes and their SNPs were represented by solid dots. The circle size and color of the dot represent the number of connection degree, red represents the maximum connection degree, and blue represents the minimum connection degree. Three genes (MBL2, LTA, and IL12RB1) and their significant SNPS were showed as red color

common diseases, which have been studied in humans through the International HapMap Project [33].

Analyses of polymorphism data based on LD and haplotype structure are becoming increasingly important; both have been successfully used to determine the association between $M B L 2$ polymorphisms and TB susceptibility. A previous study indicated that $M B L 2$ gene diplotypes might be significantly more common in $\mathrm{TB}$ patients than in the control group [24]. It is well known that the haplotype or genotype information can be statistically defined as complete or incomplete data because the genotype data can be extracted from the haplotype data, but the reverse is not true. Consequently, it seems more important to determine the association between polymorphism and phenotype based on the configuration of haplotypes and diplotypes compared with alleles and genotypes. Recently, some studies have indicated that reactions to drugs and phenotypes are associated with the arrangement of haplotypes or diplotype rather than genotypes [34], which is consistent with the results of our present study. Although there were no significant differences in the $M B L 2$ alleles observed between the TB and control groups, haplotype or diplotype configuration analysis found that the rs10824793_rs7916582*AT/AT diplotype had a significantly decreased TB risk in 1-copy logistic regression analysis compared with 0 -copy, but the rs10824793_rs7916582*GT/GT diplotype had a considerably increased TB risk.

However, the limitation of the present study is that we did not analyze the relationship between MBL levels and $\mathrm{TB}$ risk. It has been reported that serum MBL levels were significantly higher in patients with active TB than in healthy controls [35], which may protect against the early development of pulmonary TB after infection [36]. 


\section{Conclusions}

This case-control study showed, for the first time, that the rs930507 G/G, rs2099902 (C/T + C/C) vs T/T, rs930507 $(\mathrm{C} / \mathrm{G}+\mathrm{G} / \mathrm{G})$ vs $\mathrm{C} / \mathrm{C}$, and $\operatorname{rs} 10824793(\mathrm{G} / \mathrm{A}+\mathrm{G} / \mathrm{G})$ vs $\mathrm{A} / \mathrm{A}$ genotypes were associated with an increased risk of TB in the Han Chinese population. Interestingly, our findings also showed that the rs10824793_rs7916582*GT and rs10824793_rs7916582\%AT haplotypes or diplotypes were significantly associated with TB risk. These findings provide new insights into the association between SNPs in IIRGs and susceptibility to TB. However, it is necessary to confirm the findings of our study by performing further multi-centric clinical and extensive sample studies on different populations in China.

\section{Supplementary information}

Supplementary information accompanies this paper at https://doi.org/10. 1186/s40249-020-00664-9.

Additional file 1: Table S1. Genotype frequencies of 64 genotyped SNPs in the IL-10, IL18R1, IL1A, IL1B, STAT1, SLC11A1, SP110, IL12B, LTA, TNF, IFNGR1, MBL2, VDR, IL27, CCL2, IL12RB1, IFNGR2 and TLR8 genes among cases and controls and their associations with tuberculosis risk under a codominant genetic model.

Additional file 2: Table S2. Association analysis of 64 SNPs in the $/ L-10$ IL18R1, ILIA, IL1B, STAT1, SLC11A1, SP110, IL12B, LTA, TNF, IFNGR1, MBL2, $V D R, I L 27, C C L 2, I L 12 R B 1$, IFNGR2 and TLR8 genes under a dominant and recessive genetic model.

Additional file 3: Table S3. Association analysis of MBL2 SNPS between TB subgroups and healthy controls under a codominant genetic model.

Additional file 4: Table S4. Association analysis of MBL2 SNPs between TB subgroups and healthy controls under a dominant and recessive genetic model.

\section{Abbreviations}

Cls: Confidence intervals; EPTB: Extrapulmonary tuberculosis; HWE: HardyWeinberg Equilibrium; IFNGR1: Interferon gamma receptor 1; IL-

10: Interleukin-10; IL12RB1: Interleukin 12 receptor beta 1; IL18R1: Interleukin 18 receptor 1; IIRGs: Immune- and Inflammatory-Related Genes; LD: Linkage Disequilibrium; LTA: Lymphotoxin A; MAF: Minor Allele Frequency; MBL: Mannose-Binding Lectin; MCP-1 or CCL2: Monocyte chemoattractant protein-1; NRAMP1 or SLC11A1: Natural resistance-associated macrophage protein 1; ORs: Odds ratios; PCR: Polymerase Chain Reaction; PTB: Pulmonary Tuberculosis; SLC: Sodium-Lithium Countertransport; SNPS: Single-Nucleotide Polymorphisms; STAT1: Signal transducer and activator of transcription 1; TB: Tuberculosis; TLR8: Toll-like receptor 8; TNF: Tumor necrosis factor; TPTB: Total pulmonary tuberculosis; VDR: Vitamin D receptor

\section{Acknowledgments}

We would like to thank the tireless contributions of the staff in the Physical Examination Center and the Institute for Tuberculosis Research, and Editage (www.editage.cn) for English language editing.

\section{Authors' contributions}

XQW was responsible for the initial conception, study design, implementation of this study, data management, and quality control. WPG was responsible for literature search, figures making, and writing for the original draft. JXZ was accountable for the implementation of this study, data management and quality control, and data analysis. HRA, WGZ, DLZ, YRY, YL, JW, and JT were responsible for organizing investigation at the study sites, data collection and data management, and comments for this draft. WPG and XQW were responsible for funding acquisition, supervision, critical revision for the original draft, and the final decision for submission. All authors contributed to reviewing and have seen and approved this manuscript for submission.

\section{Funding}

This study was funded by the Beijing Municipal Science \& Technology Commission (Grant No. Z181100001718005 and 19 L2152); the National Natural Science Foundation of China (Grant No. 81801643); the Army

"Twelfth Five" Scientific Research Foundation (Grant No. BWS11J050); and the Chinese PLA General Hospital (Grant No. QNC19047).

\section{Availability of data and materials}

All data generated or analyzed during this study are included in this published article [and its supplementary information files].

\section{Ethics approval and consent to participate}

The study protocol was approved by the Research Ethics Committee of the 8th Medical Center of Chinese PLA General Hospital. The signed informed consent was obtained from all participants before the investigation.

\section{Consent for publication}

Not applicable.

\section{Competing interests}

The authors declare no conflict of interest. The funders had no role in the design of the study; in the collection, analyses, or interpretation of data; in the writing of the manuscript, or in the decision to publish the results.

\section{Author details}

${ }^{1}$ Army Tuberculosis Prevention and Control Key Laboratory/Beijing Key Laboratory of New Techniques of Tuberculosis Diagnosis and Treatment, Institute for Tuberculosis Research, the 8th Medical Center of Chinese PLA General Hospital, 17\# Heishanhu Road, Haidian District, Beijing 100091, China. ${ }^{2}$ Laboratory of Animal Experiment, the 8th Medical Center of Chinese PLA General Hospital, 17\# Heishanhu Road, Haidian District, Beijing 100091, China. ${ }^{3}$ Physical Examination Center, the 8th Medical Center of Chinese PLA General Hospital, 17\# Heishanhu Road, Haidian District, Beijing 100091, China. ${ }^{4}$ Department of Respiration, the 8th Medical Center of Chinese PLA General Hospital, 17\# Heishanhu Road, Haidian District, Beijing 100091, China.

Received: 5 February 2020 Accepted: 17 April 2020

Published online: 29 April 2020

\section{References}

1. WHO. Global tuberculosis report 2019. Geneva: World Health Organization; 2019

2. Small PM, Fujiwara PI. Management of tuberculosis in the United States. N Engl J Med. 2001;345(3):189-200.

3. Cooke GS, Hill AV. Genetics of susceptibility to human infectious disease Nat Rev Genet. 2001:2(12):967-77.

4. Bowdish DM, Sakamoto K, Lack NA, Hill PC, Sirugo G, Newport MJ, et al. Genetic variants of MARCO are associated with susceptibility to pulmonary tuberculosis in a Gambian population. BMC Med Genet. 2013;14:47.

5. Zhang J, Zheng L, Zhu D, An H, Yang Y, Liang Y, et al. Polymorphisms in the interleukin 18 receptor 1 gene and tuberculosis susceptibility among Chinese. PLoS One. 2014:9(10):e110734.

6. Aravindan PP. Host genetics and tuberculosis: theory of genetic polymorphism and tuberculosis. Lung India. 2019;36(3):244-52.

7. Joshi L, Chelluri LK, Valluri V, Gaddam S. Association of TNF-alpha, IL-10 and IL-6 promoter polymorphisms in pulmonary tuberculosis patients and their household contacts of younger age group. Comp Immunol Microbiol Infect Dis. 2018;56:20-6.

8. Sanchez D, Lefebvre C, Garcia LF, Barrera LF. Variants in the IFNgamma transcription factor genes TBET, STAT1, STAT4, and HLX and the risk of pulmonary tuberculosis in a Colombian population: a case-control study. Biomedica. 2013;33(2):259-67.

9. Meilang Q, Zhang Y, Zhang J, Zhao Y, Tian C, Huang J, et al. Polymorphisms in the SLC11A1 gene and tuberculosis risk: a meta-analysis update. Int J Tuberc Lung Dis. 2012;16(4):437-46.

10. Chang SY, Chen ML, Lee MR, Liang YC, Lu TP, Wang JY, et al. SP110 polymorphisms are genetic markers for vulnerability to latent and active tuberculosis infection in Taiwan. Dis Markers. 2018;2018:4687380.

11. Wu S, Liu X, Wang Y, Zhang M, Wang M, He JQ. Genetic polymorphisms of IFNG and IFNGR1 with latent tuberculosis infection. Dis Markers. 2019;2019: 8410290 . 
12. Singh B, Chitra J, Selvaraj P. CCL2, CCL3 and CCL4 gene polymorphisms in pulmonary tuberculosis patients of South India. Int J Immunogenet. 2014; 41(2):98-104.

13. Wang MG, Zhang MM, Wang $Y$, Wu SQ, Zhang M, He JQ. Association of TLR8 and TLR9 polymorphisms with tuberculosis in a Chinese Han population: a case-control study. BMC Infect Dis. 2018;18(1):561.

14. Russell DG. Who puts the tubercle in tuberculosis? Nat Rev Microbiol. 2007; 5(1):39-47.

15. Carlson CS, Eberle MA, Rieder MJ, Yi Q, Kruglyak L, Nickerson DA. Selecting a maximally informative set of single-nucleotide polymorphisms for association analyses using linkage disequilibrium. Am J Hum Genet. 2004; 74(1):106-20.

16. Buetow KH, Edmonson M, MacDonald R, Clifford R, Yip P, Kelley J, et al. High-throughput development and characterization of a genomewide collection of gene-based single nucleotide polymorphism markers by chipbased matrix-assisted laser desorption/ionization time-of-flight mass spectrometry. Proc Natl Acad Sci U S A. 2001;98(2):581-4.

17. Lewontin RC. On measures of gametic disequilibrium. Genetics. 1988;120(3): 849-52.

18. Gabriel SB, Schaffner SF, Nguyen H, Moore JM, Roy J, Blumenstiel B, et al. The structure of haplotype blocks in the human genome. Science. 2002; 296(5576):2225-9.

19. Stephens M, Donnelly P. A comparison of bayesian methods for haplotype reconstruction from population genotype data. Am J Hum Genet. 2003; 73(5):1162-9.

20. Schaid DJ, Rowland CM, Tines DE, Jacobson RM, Poland GA. Score tests for association between traits and haplotypes when linkage phase is ambiguous. Am J Hum Genet. 2002;70(2):425-34.

21. Ricklin D, Hajishengallis G, Yang K, Lambris JD. Complement: a key system for immune surveillance and homeostasis. Nat Immunol. 2010;11(9):785-97.

22. Shi J, Xie M, Wang JM, Xu YJ, Xiong WN, Liu XS. Mannose-binding lectin two gene polymorphisms and tuberculosis susceptibility in Chinese population: a meta-analysis. J Huazhong Univ Sci Technolog Med Sci. 2013; 33(2):166-71 (in Chinese).

23. Cao Y, Wang X, Cao Z, Wu C, Wu D, Cheng X. Genetic polymorphisms of MBL2 and tuberculosis susceptibility: a meta-analysis of 22 case-control studies. Arch Med Sci. 2018;14(6):1212-32.

24. Tong X, Wan Q, Li Z, Liu S, Huang J, Wu M, et al. Association between the mannose-binding lectin (MBL)-2 gene variants and serum MBL with pulmonary tuberculosis: An update meta-analysis and systematic review. Microb Pathog. 2019;132:374-80.

25. Mandal RK, Khan MA, Hussain A, Dar SA, Aloufi S, Jawed A, et al. Association of MBL2 gene polymorphisms with pulmonary tuberculosis susceptibility: trial sequence meta-analysis as evidence. Infect Drug Resist. 2019;12:185-210.

26. Areeshi MY, Mandal RK, Akhter N, Dar SA, Jawed A, Wahid M, et al. A metaanalysis of MBL2 polymorphisms and tuberculosis risk. Sci Rep. 2016;6:35728.

27. Lingappa JR, Dumitrescu L, Zimmer SM, Lynfield R, McNicholl JM, Messonnier $\mathrm{NE}_{\text {, et }}$ al. Identifying host genetic risk factors in the context of public health surveillance for invasive pneumococcal disease. PLoS One. 2011;6(8):e23413.

28. Wiertsema SP, Herpers BL, Veenhoven $\mathrm{RH}$, Salimans MM, Ruven HJ, Sanders EA, et al. Functional polymorphisms in the mannan-binding lectin 2 gene: effect on MBL levels and otitis media. J Allergy Clin Immunol. 2006;117(6): 1344-50.

29. Morrison AC, Boerwinkle E, Turner ST, Ferrell RE. Regional association-based fine-mapping for sodium-lithium countertransport on chromosome 10. Am J Hypertens. 2008;21(1):117-21.

30. Kalia N, Singh J, Sharma S, Kaur M. SNPs in 3'-UTR region of MBL2 increases susceptibility to recurrent vulvovaginal infections by altering SMBL levels. Immunobiology. 2019;224(1):42-9.

31. Ornelas AMM, Xavier-de-Carvalho C, Alvarado-Arnez LE, Ribeiro-Alves M, Rossi AD, Tanuri A, et al. Association between MBL2 haplotypes and dengue severity in children from Rio de Janeiro. Brazil Mem Inst Oswaldo Cruz. 2019;114:e190004.

32. Zanetti KA, Haznadar M, Welsh JA, Robles Al, Ryan BM, McClary AC, et al. 3'UTR and functional secretor haplotypes in mannose-binding lectin 2 are associated with increased colon cancer risk in African Americans. Cancer Res. 2012;72(6):1467-77.

33. International HapMap C. The international HapMap project. Nature. 2003; 426(6968):789-96.
34. Ito T, Inoue E, Kamatani N. Association test algorithm between a qualitative phenotype and a haplotype or haplotype set using simultaneous estimation of haplotype frequencies, diplotype configurations and diplotype-based penetrances. Genetics. 2004;168(4):2339-48.

35. Garcia-Gasalla M, Mila Llambi J, Losada-Lopez I, Cifuentes-Luna C, Fernandez-Baca V, Pareja-Bezares A, et al. Mannose-binding lectin exon 1 and promoter polymorphisms in tuberculosis disease in a Mediterranean area. Int J Immunogenet. 2014;41(4):306-11.

36. Hijikata M, Matsushita I, Hang NT, Maeda S, Thuong PH, do Tam B, et al. Age-dependent association of mannose-binding lectin polymorphisms with the development of pulmonary tuberculosis in Viet Nam. Hum Immunol. 2014;75(8):840-6.
Ready to submit your research? Choose BMC and benefit from:

- fast, convenient online submission

- thorough peer review by experienced researchers in your field

- rapid publication on acceptance

- support for research data, including large and complex data types

- gold Open Access which fosters wider collaboration and increased citations

- maximum visibility for your research: over $100 \mathrm{M}$ website views per year

At BMC, research is always in progress.

Learn more biomedcentral.com/submissions 